\title{
Retraction Note: Retraction of a Plagiarized Article: Period of vibrations of framed structures
}

\author{
K. Demagh $\cdot$ H. Chabil $\cdot$ H. Turkia
}

Published online: 10 February 2012

(C) RILEM 2012

\section{Retraction note to: Materials and Structures (2006) 39:259-267 DOI 10.1617/s11527-005-9008-5}

A careful analysis of the paper entitled "Period of vibrations of framed structures" published in Volume 39 of Materials and Structures (2006), pp. 259-267 has led me to the conclusion that this contribution was essentially similar to another paper authored by professor H. Adeli entitled "Approximate Formulae for Period of Vibrations of Building Systems", which had been published in 1985 in Volume 4 (issue number 1) of the International Journal of Civil Engineering for Practicing and Design Engineers, pp. 93-128. In fact more than $75 \%$ of the text in professor Adeli's original contribution (including all the key equations) was reproduced without any form of autorisation in the paper authored by K. Demagh, H. Chabil, and H. Turkia.

This is clearly a case of plagiarism that goes against the publication policy of Materials and Structures and Springer. This is why I have asked our publisher to attach the present retraction note to the paper authored by K. Demagh, H. Chabil, and H. Turkia.

Materials and Structures, as any other journal published by Springer, prides itself on the publication of high-quality and original contributions. I offer my sincere apologies to professor Adeli for this unacceptable situation.
Jacques Marchand Editor-in-Chief

The online version of the original article can be found under doi:10.1617/s11527-005-9008-5.

K. Demagh $(\bowtie)$

Department of Civil Engineering, University of Batna,

Batna, Algeria

H. Chabil

Department of Civil Engineering,

University of Constantine, Constantine, Algeria

H. Turkia

University of Batna, Batna, Algeria 